Crack Detection in Folded Plates with Back-Propagated Artificial Neural Network

Dr. Can Gonenli* ${ }^{a *}$ Dr. Oguzhan Das ${ }^{\mathrm{b}}$ and Duygu Bagci Das ${ }^{\mathrm{c}}$

${ }^{a}$ Department of Machine Drawing and Construction, Ege Vocational School, Ege

University, Izmir, Turkey, 0000-0001-9163-1569

${ }^{b}$ Department of Motor Vehicles and Transportation Technologies, Bergama Vocational School, Dokuz Eylul University, Izmir, Turkey, 0000-0001-7623-9278

${ }^{c}$ Department of Computer Technologies, Bergama Vocational School, Dokuz Eylul University, Izmir, Turkey, 0000-0003-4519-3531

*can.gonenli@ege.edu.tr, ORCID: 0000-0001-9163-1569 


\title{
Crack Detection in Folded Plates with Back-Propagated Artificial Neural Network
}

\begin{abstract}
Engineering structures may face various damages such as crack, delamination, and fatigue in several circumstances. Localizing such damages becomes essential to understand the health of the structures since they may not be able to operate anymore. Among the damage detection techniques, non-destructive methods are considerably more preferred than destructive methods since damage can be located without affecting the structural integrity. However, these methods have several drawbacks in terms of detecting abilities, time consumption, cost, and hardware or software requirements. Employing artificial intelligence techniques could overcome such issues and could provide a powerful damage detection model if the technique is utilized correctly. In this study, the crack localization in flat and folded plate structures has been conducted by employing a Back-propagated Artificial Neural Network (BPANN). For this purpose, cracks with 18 different dimensions have been modeled in flat and four different folded structures by utilizing the Finite Element Method. The dataset required to perform the crack localization procedure includes the first ten natural frequencies of all structures as input variables. As output variables, the dataset contains a total of 500 crack locations for five structures. It is concluded that the BPANN can localize all cracks with an average accuracy of $95.12 \%$.
\end{abstract}

Keywords: Finite Element Method, Crack Detection, Machine Learning, Vibration, Neural Network, Folded Plate.

\section{Introduction}

Different types of damage may occur in engineering structures due to production or usage area. Damages such as cracks, regional inhomogeneity, variability in the cross-sectional area, delamination, and decomposition directly affect the rigidity of the structure. Errors that can be detected by destructive testing methods also bring many economic problems. For this reason, it is of great importance to determine the location of the damage by non-destructive methods in order to detect the instabilities that will be caused by the damage in the structures. The need for new methods in terms of economy, speed, and applicability is increasing day by day.

Tsou and Shen performed a methodology for on-line damage identification of discrete structural systems. The location and severity of the damage can be detected using neural networks [1]. Yam et al. presented an integrated method for damage detection of composite structures using their vibration responses, wavelet transform and artificial neural networks identification [2]. Yam et al. introduced vibration-based online and non-destructive detection technology for structural damage. A honeycomb sandwich plate is subjected for the dynamic response. Wavelet transformation of three experimental plates contain a crack is obtained [3]. Yeung and Smith investigated a damage detection procedure, using pattern recognition of the vibration signature, was assessed using a finite element model of a real structure [4]. Chen et al. 
investigated a dynamic-based damage detection method for structural systems. The HilbertHuang transform has been used and the method is implemented the scheme on a model of wingbox [5]. Manoach and Trendafilova used large amplitude vibrations the detect damages on the fully clamped rectangular plates. The geometrically nonlinear version of the Mindlin plate theory is used to model the plate behavior, and the damage is represented as a stiffness reduction in a small area of the plate [6]. Paulraj et al. presented a simple method for crack identification in steel plates based on statistical time energy. The plate is excited by an impulse signal. A simple neural network model trained by back propagation algorithm [7]. Shih et al. used dynamic computer simulation techniques to develop and apply a procedure for the structural damage detection in flexural members in building and bridge structures [8]. Elshafey et al. investigated the damage detection in offshore jacket platform structures subjected to random loads using a combined method of random decrement signature and neural networks [9]. Paulraj et al. presented a simple method for crack identification in steel plates based on the frame based frequency domain features. Discrete Fourier Transformation is computed for the propagated vibration signals. Two simple neural network models were developed [10]. Nasiri et al. used the frequency response and modal analysis of a composite plate to detect and localize the delamination. Artificial neural network process, the experimental results, and the finite element model are used together for two different damaged plates [11]. Paulraj et al. examined the damage detection in steel plates using nondestructive vibration testing. The simply supported steel plate is used to develop a simple experimental model [12]. Kourehli examined a method for damage detection of plate structures. The extreme learning machine is proposed, which includes the mode shapes and the natural frequencies of a damaged plate. Several damages are applied to two examples, with and without noise in the modal data [13]. Alexandrino et al. investigated a robust optimization for the damage detection as an inverse problem. The localization and identification of damage is performed through artificial neural network [14]. Pan et al. investigates the selection of vibration modes for improving accuracy of frequencybased damage detection with using noise signals. A case study on a composite curved plate is presented [15]. Tan et al. developed a procedure for detecting damage in composite bridge structure and I beams. The procedure depends on the vibration characteristics and the artificial neural network for the modal strain energy-based damages [16]. Padil et al. examined the frequency response function as the input variable for artificial neural network for damage detection. The study presents a combination of a non-probabilistic method with Principal component analysis to consider the problem of the existing uncertainties [17]. Oliver et al. performed a neural network-based damage identification in laminated composite plates. Finite element software is employed for the plate model. The quantify damage severity achieved up to $95 \%$ success rate [18].

The non-destructive methods have several drawbacks in terms of detecting abilities, time consumption, cost, and hardware or software requirements. Employing artificial intelligence techniques may overcome such issues since they can detect damages with high accuracy in a short time and do not require powerful hardware or software only if they modeled in the right way. In this study, it is aimed to detect crack locations in isotropic thin plate structures by using Back-propagated Artificial Neural Network (BPANN) considering the free vibration responses. 
Vibration responses have a significant role in crack detection since cracks of different sizes and directions in the structures affect the natural frequency of the structure according to the relevant mode shape [19]. Each crack has been modeled in 100 different locations of flat and four different folded plates. The first ten natural frequency results are obtained for all crack sizes by using the Finite Element Method and the Classical Plate Theory (CPT). Therefore, a dataset has been obtained, which includes the first ten natural frequencies of cracked structures and corresponding crack locations. The damage localization procedure has been conducted by employing BPANN. For training and testing, a 5-fold cross-validation technique has been employed in which the train-test split has been performed randomly 5 times by considering a 80\%-20\% train-test ratio. The localization accuracies have been evaluated for each location that the cracks have been modeled.

\section{Methodology}

Shear deformation is negligible in thin and moderately thin plates [19-21]. Thus, the Classical Plate Theory (CPT) is suitable to moderately thin and very thin plates. The higher-order theories are effective for thick plates. Since thin plates are considered within the scope of this work, the CPT and the four node quadrilateral finite element are employed.

\subsection{Finite element model}

The CPT includes five different displacements as out-of-plane and in-plane. Figure-1 shows the plate model with displacements.

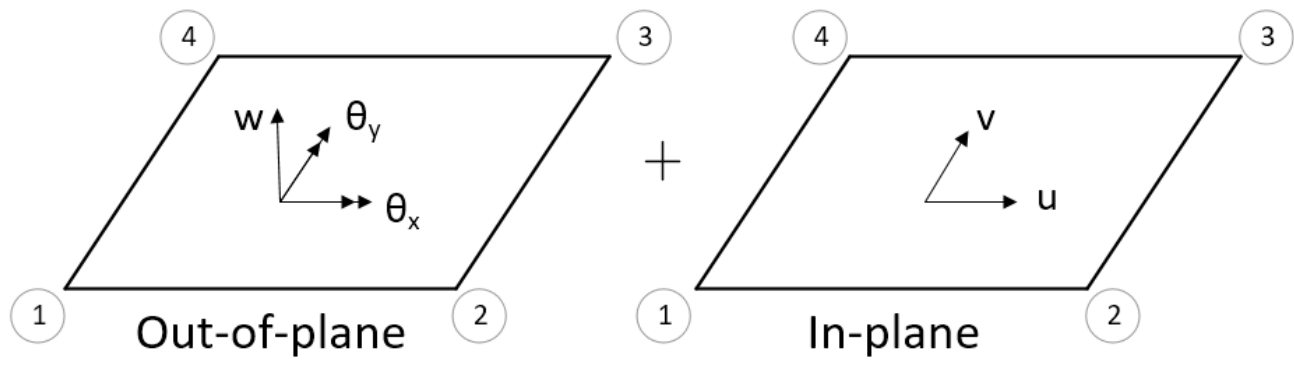

Figure 1. Four-node finite element with the out-of-plane and in-plane displacements

Normals to the middle surface of the undeformed plate remain straight and normal to the middle surface during deformation and are inextensible for in-plane movement [22, 23]. Thus, the components of in-plane displacements $u$ and $v$ can be represented by

$$
\begin{aligned}
& u=q_{1}+q_{2} \mathrm{x}+q_{3} \mathrm{y}+q_{4} x y \\
& v=q_{5}+q_{6} \mathrm{x}+q_{7} \mathrm{y}+q_{8} x y
\end{aligned}
$$

where $q_{1}-q_{8}$ are the coefficients of the in-plane displacements. The displacement functions are required and that is: 


$$
\begin{aligned}
& u=\sum_{j=1}^{4} N_{1 j} u_{j} \\
& v=\sum_{j=1}^{4} N_{1 j} v_{j}
\end{aligned}
$$

The shape function $N_{l j}$ is required the represent displacement functions. The shape functions for the in-plane displacements as follows for the non-dimensional coordinates of node $j$ by $\left(\xi_{j}\right.$, $\left.\eta_{j}\right)$ :

$$
N_{1 j}=\frac{1}{4}\left(1+\xi_{i} \xi\right)\left(1+\eta_{i} \eta\right)
$$

The displacement function for bending is shown in equation (4) in natural coordinates $(\xi, \eta)$.:

$$
\begin{gathered}
w=q_{9}+q_{10} \xi+q_{11} \eta+q_{12} \xi^{2}+q_{13} \xi \eta+q_{14} \eta^{2}+q_{15} \xi^{3}+q_{16} \xi^{2} \eta+q_{17} \xi \eta^{2}+q_{18} \eta^{3} \\
+q_{19} \xi^{3} \eta+q_{20} \xi \eta^{3}
\end{gathered}
$$

The coefficients $q_{9}$ to $q_{20}$ can be expressed in terms of the components of displacement at the four node points. The displacement functions are required and that is:

$$
w=\left[N_{21}(\xi, \eta) \quad N_{22}(\xi, \eta) \quad N_{23}(\xi, \eta) \quad N_{24}(\xi, \eta)\right]\{w\}_{e}=\left[N_{2}(\xi, \eta)\right]\{w\}_{e}
$$

The plate bending element's shape function is given in equation (6) for node $j$ ( 1 to 4 ).

$$
N_{2 j}^{T}(\xi, \eta)=\left[\begin{array}{c}
\frac{1}{8}\left(1+\xi_{j} \xi\right)\left(1+\eta_{j} \eta\right)\left(2+\xi_{j} \xi+\eta_{j} \eta-\xi^{2}-\eta^{2}\right) \\
\frac{b}{2}\left(1+\xi_{j} \xi\right)\left(\eta_{j}+\eta\right)\left(\eta^{2}-1\right) \\
-\frac{a}{2}\left(\xi_{j}+\xi\right)\left(\xi^{2}-1\right)\left(1+\eta_{j} \eta\right)
\end{array}\right]
$$

where $u_{0}, v_{0}$ and $w_{0}$ are the components of displacement at a point $(x, y)$ in the middle surface. It is necessary to include both the in-plane and bending displacements as they are coupled for some stacking sequences. The matrix form of the components of strain are as follows.

$$
\{\varepsilon\}=\left\{\begin{array}{c}
\varepsilon_{x} \\
\varepsilon_{y} \\
\Upsilon_{x y}
\end{array}\right\}=\left[\begin{array}{c}
\frac{\partial u_{0}}{\partial x} \\
\frac{\partial v_{0}}{\partial y} \\
\frac{\partial u_{0}}{\partial y}+\frac{\partial v_{0}}{\partial x}
\end{array}\right]-z\left[\begin{array}{c}
\frac{\partial^{2} w_{0}}{\partial x^{2}} \\
\frac{\partial^{2} w_{0}}{\partial y^{2}} \\
2 \frac{\partial^{2} w_{0}}{\partial x \partial y}
\end{array}\right]
$$

That is 


$$
\{\varepsilon\}=\left\{\varepsilon_{1}\right\}-z\left\{\varepsilon_{2}\right\}
$$

The strain energy of the plate is shown in equation (9) [22].

$$
U=\frac{1}{2} \int_{V} \sigma^{T} \varepsilon d V
$$

$\sigma$ represents the stress matrix, and $\varepsilon$ represents the strain matrix. The relation of the stress-strain is presented in equation (10).

$$
\sigma=D \varepsilon
$$

The strain energy is formed in equation (11).

$$
U=\frac{1}{2} h \int_{A}\{\varepsilon\}^{T}[D]\{\varepsilon\} d A
$$

Here $h$ represents the plate thickness, and $D$ represents the material matrix. Extending equation (11) gives

$$
U=\frac{1}{2} \int_{A}\left(\left\{\varepsilon_{1}\right\}^{T}\left[D_{1}\right]\left\{\varepsilon_{1}\right\}+\left\{\varepsilon_{2}\right\}^{T}\left[D_{2}\right]\left\{\varepsilon_{2}\right\}\right) d A
$$

where $D_{1}$ and $D_{2}$ are:

$$
\begin{gathered}
{\left[D_{1}\right]=\frac{E h^{3}}{12\left(1-v^{2}\right)}\left[\begin{array}{ccc}
1 & v & 0 \\
v & 1 & 0 \\
0 & 0 & \frac{1-v}{2}
\end{array}\right]} \\
{\left[D_{2}\right]=\frac{E}{\left(1-v^{2}\right)}\left[\begin{array}{ccc}
1 & v & 0 \\
v & 1 & 0 \\
0 & 0 & \frac{1-v}{2}
\end{array}\right]}
\end{gathered}
$$

Substituting equations (2) and (3) at $\varepsilon_{1}$, equations (5) and (6) at $\varepsilon_{2}$ in equation (8) and equation (12) is rearranged;

$$
U=\frac{1}{2}\{q\}^{T}\left[K_{e}\right]\{q\}
$$

$K_{e}$ represents the element stiffness matrix in dimension (20x20). The kinetic energy relation is given in equation (21) for the average density $\rho$ and the thickness of the laminate is $h$. 


$$
T=\frac{1}{2} \int_{A} \rho h\left(\dot{u}^{2}+\dot{v}^{2}+\dot{w}^{2}\right) d A
$$

Equation (15) is rearranged using equations (2) and (5);

$$
T=\frac{1}{2}\{\dot{q}\}^{T}\left[M_{e}\right]\{\dot{q}\}
$$

$M_{e}$ represents the (20x20) element mass matrix. The drilling effect $\left(\theta_{z}\right)$ needs to be considered to satisfy the degrees of freedom. Therefore, the last value has to be added formally into matrices for the drilling effect, although these matrices represent the effect of $\theta_{z}$. Hence the element stiffness and mass matrices are expanded to $(24 \times 24)$ from $(20 \times 20)$. The corresponding diagonal values of $\left[\theta_{z}\right]_{4 \times 4}$ has taken absolute value that $1 / 1000$ of the minimum value in $(20 \times 20)$ stiffness and mass matrices, while other values of $\left[\theta_{z}\right]_{4 \times 4}$ are considered to be zero $[19,24]$. The generalized displacement vector of the $j^{\text {th }}$ node for local reference coordinates is expressed as:

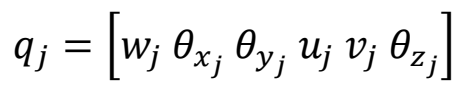

Figure 2 shows the coordinate system transformation.

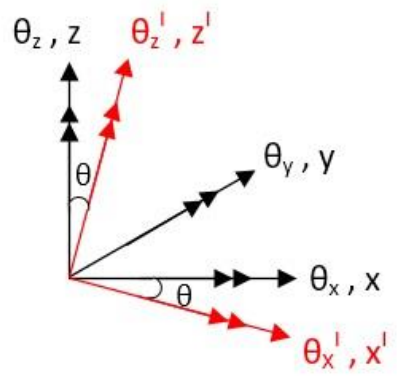

Figure 2. Coordinate system transformation.

The transformation matrix is given in equation (18) which includes six generalized coordinates.

$$
\operatorname{Tr}=\left[\begin{array}{cccccc}
\cos (\theta) & 0 & 0 & -\sin (\theta) & 0 & 0 \\
0 & \cos (\theta) & 0 & 0 & 0 & \sin (\theta) \\
0 & 0 & 1 & 0 & 0 & 0 \\
\sin (\theta) & 0 & 0 & \cos (\theta) & 0 & 0 \\
0 & 0 & 0 & 0 & 1 & 0 \\
0 & -\sin (\theta) & 0 & 0 & 0 & \cos (\theta)
\end{array}\right]
$$

\subsection{Crack model}

Figure 3 shows the obtaining procedure of a finite element model with crack. The different 
directed cracks can be implemented by changing the dimensions of the crack. The cracked finite element is obtained by subtracting the stiffness of crack from the element stiffness matrix.

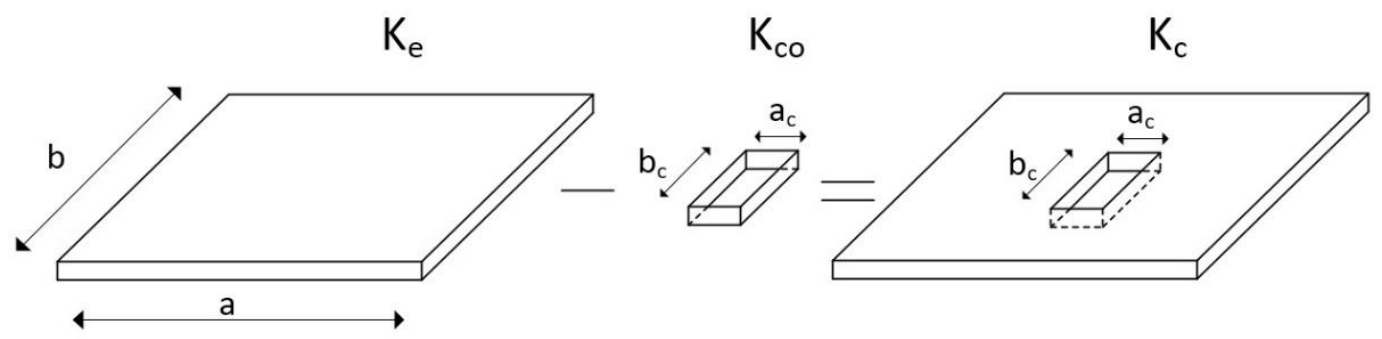

Figure 3. The obtainment process of the cracked finite element [21].

$K_{e}$ is calculated from equation (19) in finite element dimensions and $K_{c o}$ is calculated in crack dimensions. The $K_{c o}$ is subtracted from the element stiffness matrix $\left(K_{e}\right)$ then the cracked element stiffness matrix $\left(K_{c}\right)$ is obtained. The free vibration analysis is repeated with the $\left(K_{c}\right)$ matrix inplaced separately instead of each finite element stiffness matrix $\left(K_{e}\right)$ [19].

$$
K_{c}=K_{e}-K_{c o}
$$

\subsection{Free vibration analysis}

The element stiffness matrix $K_{e}$, and the element mass matrix $M_{e}$ are used to form global stiffness $(K)$, and global mass $(M)$ matrices. The dynamic response of a plate is formulated through Lagrange's equation of motion (20) [22].

$$
[M]\{\ddot{\mathrm{q}}\}+[K]\{\mathrm{q}\}=0
$$

Natural frequencies are calculated from the eigenvalue problem given in equation (21). Here, $\omega$ is the natural frequency value.

$$
[K]-\omega^{2}[M]=0
$$

\subsection{Artificial neural network}

Following the evaluation of the damaged and healthy natural frequencies, they are used for damage detection in flat and folded plate structures. For this purpose, the first 10 natural frequency ratios (the ratio of the natural frequency of the damaged to the healthy structure) are considered to train and test the Artificial Neural Network (ANN).

Artificial Neural Networks are powerful mathematical models, which mimic the biological neuron's structure. A basic ANN structure, shown in Figure 4, includes input units, hidden layer units, and output units. The input units $\left(x_{i}\right)$ are connected to the hidden units by dendrites in which the input and dendrite weight $\left(w_{0 i}\right)$ are multiplied. In the hidden units, the weighted input $\left(w_{i}\right)$ is produced and substituted into an activation function $(f)$, which differs with respect to the 
type of the neural network. Afterward, the activation function is summed with bias $(b)$ to evaluate the final output. The bias is evaluated for each training step where the initial outputs are evaluated. If the initial outputs are considerably different from the actual outputs, the weights are adjusted by the bias value. By doing so, the outputs of the neural networks become closer to the actual outputs. As the error between the actual and neural network outputs becomes negligible or small, the learning procedure is finalized. Therefore, the error can be calculated as [25]

$$
\mathrm{e}=\frac{1}{2} \sum_{i=1}^{m}|| y_{i}-o_{i} \|\left.\right|^{2}
$$

where $y_{i}$ is the vector of actual values and $o_{i}$ is the output vector of ANN model. Considering a single neuron with $m$ inputs, the output vector is evaluated by

$$
\mathrm{o}_{\mathrm{i}}=\sum_{i}^{m} \theta\left(x_{i} w_{0_{i}}+b\right)
$$

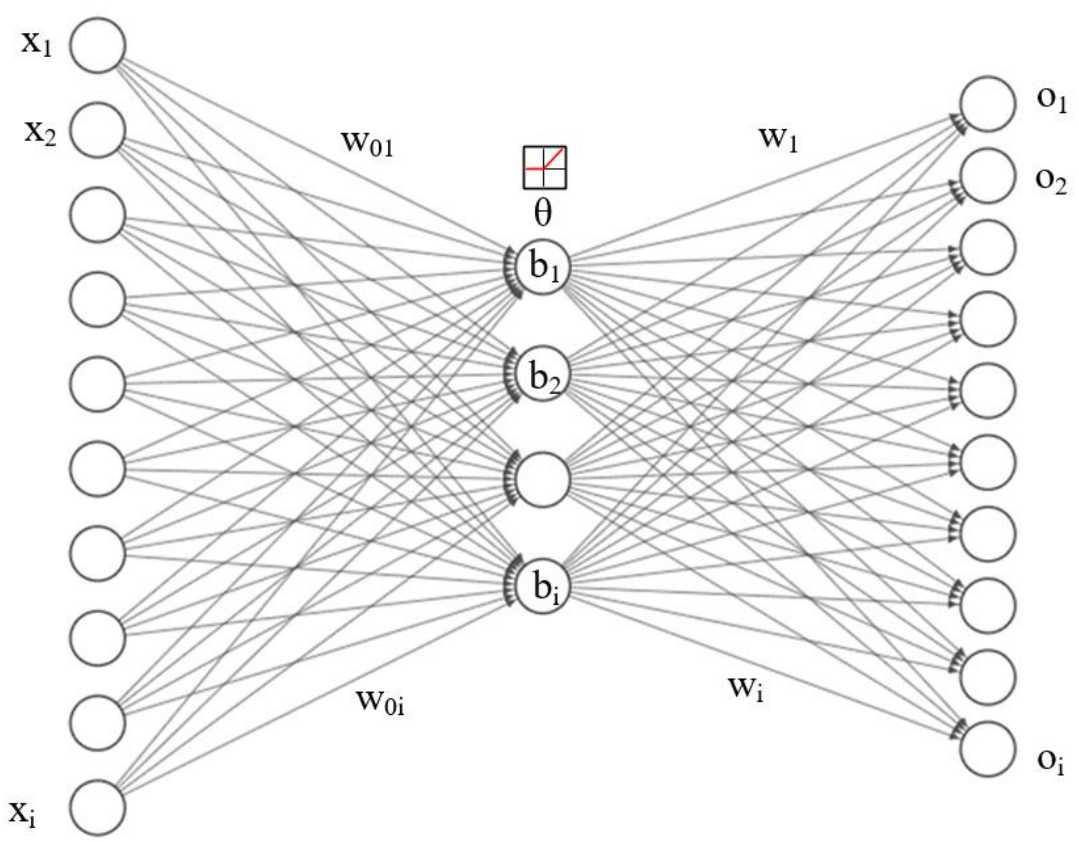

Figure 4. The architecture of an artificial neural network.

This fundamental procedure may vary depending on the type of neural network (e.g., feedforward, back-propagated, radial basis function, etc.) and it may have been improved by changing the number of hidden neurons or hidden layers. On the other hand, detailed analyses have to be performed when selecting the activation function, the number of hidden neurons, and hidden layers since they may adversely affect the performance of the neural network. 


\section{Results}

Within the scope of the study, five different plates, one straight and four folded, are investigated. Folded plates are obtained by bending the flat plate in the middle without changing its dimensions. Figure 5 shows the flat and folded plate structures.
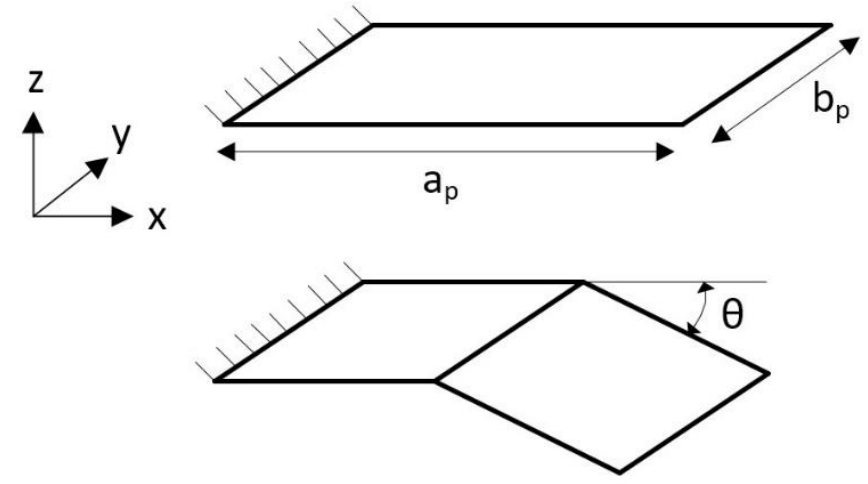

Figure 5. Flat and folded plate structures.

A total of 18 different sizes of cracks are modelled in each plate structure individually. The cracks are divided equally into two categories called $\mathrm{x}$-dependent and y-depended cracks whose lengths vary in $\mathrm{x}$ - and $\mathrm{y}$ - axis respectively. Figure 6 shows the illustration of $\mathrm{x}$-dependent and $\mathrm{y}$-dependent cracks. Table 1 gives material properties, plate geometries, and crack dimensions.

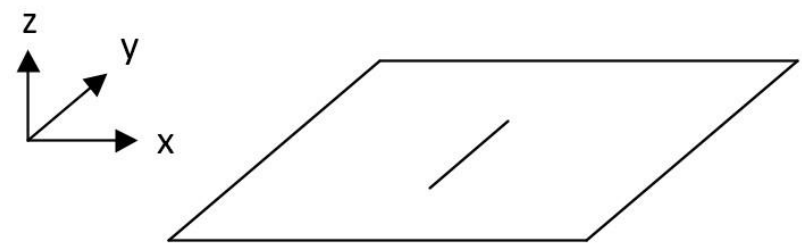

(a)

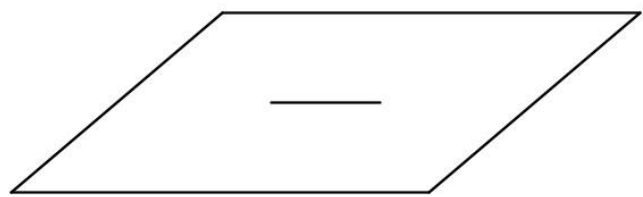

(b)

Figure 6. Cracked finite element. (a) x-dependent crack, (b) y-dependent crack.

Table 1. Material specifications and the dimensions of the plates

\begin{tabular}{ccc}
\hline \hline Symbol & Name & Quantity, Order \\
\hline$E$ & Modulus of Elasticity & $200 \mathrm{GPa}$ \\
$\rho$ & Mass density & $7900 \mathrm{~kg} / \mathrm{m}^{3}$ \\
$v$ & Poisson's ratio & 0.30 \\
$a_{p}$ & Plate length & $0.5 \mathrm{~m}$ \\
$b_{p}$ & Plate width & $0.5 \mathrm{~m}$ \\
$h$ & Thickness of the plate & $0.005 \mathrm{~m}$ \\
$\ldots$ & Mesh density & $10 \times 10$
\end{tabular}



$a_{c} / b_{c}$
X-dependent crack length/width
1:0.5:5 / $25 \mathrm{~mm}$
$a_{c} / b_{c}$
y-dependent crack length/width
25 / 1:0.5:5 mm
$\theta_{1}, \theta_{2}, \theta_{3}, \theta_{4}$
Angles of the folded plates
$15^{0}, 30^{0}, 45^{0}, 60^{0}$

The convergence analysis of the flat and four different folded healthy plates is presented in Table 2. Convergence analyzes are performed both in ANSYS and MATLAB for healthy structures, in case the structure has x-dependent cracks located in the middle of the folded part seen in Figure-5, and y-dependent cracks located in the middle of the folded part of the plate. While the natural frequency parameters of the cracked structure remain the same or decrease in both ANSYS and MATLAB compared to the healthy structure, it is seen that more sensitive results are obtained with MATLAB. The non-dimensional natural frequency parameter $(\lambda)$ is given in Equation (24), where $\omega$ is natural frequency, $A$ is cross-section area of the plate, $I$ is the area moment of inertia.

$$
\lambda=\omega \sqrt{\frac{\rho A a_{p}^{4}}{E I}}
$$

Table 2. Convergence analysis of healthy and damaged plates

\begin{tabular}{|c|c|c|c|c|c|c|c|c|c|c|c|c|}
\hline & & & $\lambda_{1}$ & $\lambda_{2}$ & $\lambda_{3}$ & $\lambda_{4}$ & $\lambda_{5}$ & $\lambda_{6}$ & $\lambda_{7}$ & $\lambda_{8}$ & $\lambda_{9}$ & $\lambda_{10}$ \\
\hline \multirow{6}{*}{$\begin{array}{l}\frac{\vec{\pi}}{\pi} \\
\frac{\pi}{\pi}\end{array}$} & \multirow{2}{*}{ Healthy } & MATLAB & 5.59 & 14.01 & 35.23 & 43.37 & 51.10 & 87.99 & 100.34 & 106.63 & 116.11 & 148.72 \\
\hline & & ANSYS & 5.79 & 14.17 & 35.52 & 45.35 & 51.58 & 90.21 & 102.32 & 107.04 & 118.40 & 154.78 \\
\hline & \multirow{2}{*}{$\begin{array}{l}\text { Cracked } \\
\text { (x-dep.) }\end{array}$} & MATLAB & 5.58 & 13.73 & 35.22 & 43.35 & 51.05 & 87.97 & 100.34 & 106.40 & 116.03 & 148.61 \\
\hline & & ANSYS & 5.79 & 14.17 & 35.49 & 45.30 & 51.55 & 90.21 & 102.04 & 107.01 & 118.36 & 154.76 \\
\hline & \multirow{2}{*}{$\begin{array}{l}\text { Cracked } \\
\text { (y-dep.) }\end{array}$} & MATLAB & 5.38 & 13.99 & 34.95 & 43.37 & 51.04 & 87.84 & 100.31 & 106.61 & 116.09 & 148.60 \\
\hline & & ANSYS & 5.79 & 14.17 & 35.50 & 45.18 & 51.55 & 90.21 & 102.23 & 106.95 & 118.36 & 154.75 \\
\hline \multirow{6}{*}{$\begin{array}{l}\frac{0}{0} \\
\frac{\pi}{2} \\
0 \\
\frac{0}{0} \\
0 \\
\text { i } \\
\text { in }\end{array}$} & \multirow{2}{*}{ Healthy } & MATLAB & 5.63 & 14.17 & 34.11 & 48.27 & 61.11 & 100.30 & 115.85 & 122.87 & 150.52 & 183.43 \\
\hline & & ANSYS & 5.86 & 14.09 & 35.33 & 48.62 & 61.72 & 102.16 & 114.70 & 126.50 & 153.08 & 183.78 \\
\hline & \multirow{2}{*}{$\begin{array}{l}\text { Cracked } \\
\text { (x-dep.) }\end{array}$} & MATLAB & 5.62 & 13.92 & 34.10 & 48.21 & 61.11 & 100.30 & 115.84 & 122.53 & 150.52 & 183.42 \\
\hline & & ANSYS & 5.86 & 14.08 & 35.29 & 48.59 & 61.70 & 101.86 & 114.68 & 126.45 & 153.01 & 183.43 \\
\hline & \multirow{2}{*}{$\begin{array}{l}\text { Cracked } \\
\text { (y-dep.) }\end{array}$} & MATLAB & 5.46 & 14.15 & 33.90 & 48.21 & 61.04 & 100.27 & 115.81 & 122.82 & 150.51 & 183.34 \\
\hline & & ANSYS & 5.86 & 14.08 & 35.32 & 48.59 & 61.61 & 102.07 & 114.68 & 126.40 & 153.05 & 183.64 \\
\hline \multirow{6}{*}{$\begin{array}{l}\frac{0}{\pi} \\
\frac{0}{0} \\
\frac{d}{0} \\
\frac{0}{0} \\
\text { I } \\
8 \\
0\end{array}$} & \multirow{2}{*}{ Healthy } & MATLAB & 5.76 & 14.67 & 31.33 & 42.55 & 61.91 & 100.25 & 115.97 & 123.58 & 153.37 & 180.29 \\
\hline & & ANSYS & 6.00 & 13.97 & 32.55 & 42.78 & 63.38 & 102.16 & 115.37 & 128.25 & 155.62 & 180.86 \\
\hline & \multirow{2}{*}{$\begin{array}{l}\text { Cracked } \\
\text { (x-dep.) }\end{array}$} & MATLAB & 5.75 & 14.47 & 31.32 & 42.49 & 61.90 & 100.25 & 115.95 & 123.24 & 153.36 & 180.28 \\
\hline & & ANSYS & 6.00 & 13.96 & 32.52 & 42.76 & 63.37 & 101.85 & 115.35 & 128.19 & 155.51 & 180.53 \\
\hline & \multirow{2}{*}{$\begin{array}{l}\text { Cracked } \\
\text { (y-dep.) }\end{array}$} & MATLAB & 5.59 & 14.66 & 31.14 & 42.50 & 61.83 & 100.22 & 115.92 & 123.53 & 153.34 & 180.27 \\
\hline & & ANSYS & 6.00 & 13.96 & 32.54 & 42.76 & 63.27 & 102.06 & 115.34 & 128.16 & 155.58 & 180.75 \\
\hline \multirow{4}{*}{$\begin{array}{l}\text { D } \\
0 \\
\frac{0}{0} \\
\text { I } \\
\text { in } \\
\text { f }\end{array}$} & \multirow{2}{*}{ Healthy } & MATLAB & 5.98 & 15.56 & 28.00 & 37.50 & 62.08 & 100.32 & 116.14 & 123.64 & 153.75 & 167.84 \\
\hline & & ANSYS & 6.23 & 16.19 & 29.16 & 37.72 & 64.89 & 102.27 & 116.21 & 130.12 & 156.00 & 169.76 \\
\hline & \multirow{2}{*}{$\begin{array}{l}\text { Cracked } \\
\text { (x-dep.) }\end{array}$} & MATLAB & 5.98 & 15.40 & 28.00 & 37.43 & 62.07 & 100.31 & 116.13 & 123.31 & 153.75 & 167.83 \\
\hline & & ANSYS & 6.24 & 16.18 & 29.14 & 37.70 & 64.88 & 101.94 & 116.20 & 130.06 & 155.86 & 169.44 \\
\hline
\end{tabular}




\begin{tabular}{|c|c|c|c|c|c|c|c|c|c|c|c|c|}
\hline & \multirow{2}{*}{$\begin{array}{l}\text { Cracked } \\
\text { (y-dep.) }\end{array}$} & MATLAB & 5.81 & 15.54 & 27.83 & 37.45 & 62.00 & 100.28 & 116.10 & 123.59 & 153.72 & 167.83 \\
\hline & & ANSYS & 6.24 & 16.18 & 29.16 & 37.70 & 64.78 & 102.17 & 116.19 & 130.03 & 155.94 & 169.66 \\
\hline & \multirow{2}{*}{ Healthy } & MATLAB & 6.32 & 16.64 & 24.91 & 33.86 & 62.15 & 100.59 & 116.42 & 123.63 & 153.86 & 159.40 \\
\hline & & ANSYS & 6.59 & 17.33 & 25.97 & 34.07 & 64.53 & 102.58 & 116.29 & 129.32 & 155.90 & 162.00 \\
\hline & & MATLAB & 6.31 & 16.53 & 24.90 & 33.78 & 62.14 & 100.59 & 116.41 & 123.30 & 153.86 & 159.39 \\
\hline & & ANSYS & 6.59 & 17.33 & 25.96 & 34.05 & 64.52 & 102.23 & 116.27 & 129.26 & 155.71 & 161.75 \\
\hline & \multirow{2}{*}{$\begin{array}{l}\text { Cracked } \\
\text { (y-dep.) }\end{array}$} & MATLAB & 6.13 & 16.62 & 24.76 & 33.82 & 62.07 & 100.56 & 116.38 & 123.58 & 153.83 & 159.39 \\
\hline & & ANSYS & 6.59 & 17.33 & 25.97 & 34.05 & 64.42 & 102.47 & 116.27 & 129.22 & 155.83 & 161.92 \\
\hline
\end{tabular}

The crack localization has been performed using Python 3.9. The ANN model has been employed by considering Back-propagated Multi-Layer Perceptron Classifier [26] that existed in Scikit-learn, which is a powerful and flexible library for developing artificial intelligence models. The ANN models have been built considering the $\mathrm{x}$ and $\mathrm{y}$ locations of the cracks. Therefore, for each crack category, a total of four ANN models have been developed to determine the locations of the crack in terms of the $\mathrm{x}$ - and $\mathrm{y}$-axis. For all models, relu transfer function and single hidden layer have given the best results. On the other hand, the hidden neuron number per hidden layer and the L2 penalty parameter vary for each model. Therefore, the best hidden neuron numbers are 18 and 130 for the $\mathrm{x}$ and $\mathrm{y}$ locations of the $\mathrm{y}$-dependent cracks, 4 and 10 for the $\mathrm{x}$ and $\mathrm{y}$ locations of the $\mathrm{x}$-dependent cracks respectively. In addition, the L2 penalty parameter values are 0.01 and 0.0001 for the $\mathrm{x}$ and $\mathrm{y}$ locations of the first case, 0.001 and 0.0001 for the $\mathrm{x}$ and $\mathrm{y}$ locations of the second case respectively. Considering the ANN models of which parameters are given above, the damage localization analysis has been performed. Table 3 shows the accuracy and standard deviation values of localizing the $\mathrm{x}$ dependent and y-dependent cracks in the flat and folded plate structures.

Table 3. The accuracy and standard deviation of localizing the $\mathrm{x}$-dependent and y-dependent cracks

\begin{tabular}{|c|c|c|c|c|c|c|c|}
\hline \multicolumn{4}{|c|}{ X-Dependent Cracks Accuracy } & \multicolumn{4}{|c|}{ Y-Dependent Cracks Accuracy } \\
\hline Structure & $\begin{array}{c}x \text {-axis } \\
\left(a_{p}\right) \\
\end{array}$ & $y$-axis $\left(b_{p}\right)$ & Average & Structure & $x$-axis $\left(a_{p}\right)$ & $y$-axis $\left(b_{p}\right)$ & Average \\
\hline Flat Plate & 98.67 & 97.67 & 98.17 & Flat Plate & 99.22 & 98.56 & 98.89 \\
\hline $\begin{array}{c}\text { Folded Plate } \\
\left(15^{0}\right)\end{array}$ & 99.67 & 90.56 & 95.11 & $\begin{array}{c}\text { Folded } \\
\text { Plate }\left(15^{0}\right)\end{array}$ & 99.44 & 89.44 & 94.44 \\
\hline $\begin{array}{l}\text { Folded Plate } \\
\left(30^{0}\right)\end{array}$ & 99.89 & 90.22 & 95.06 & $\begin{array}{c}\text { Folded } \\
\text { Plate }\left(30^{\circ}\right)\end{array}$ & 98.56 & 90.44 & 94.5 \\
\hline $\begin{array}{c}\text { Folded Plate } \\
\left(45^{\circ}\right)\end{array}$ & 99.89 & 90.22 & 95.06 & $\begin{array}{c}\text { Folded } \\
\text { Plate }\left(45^{\circ}\right)\end{array}$ & 97.44 & 86.89 & 92.17 \\
\hline $\begin{array}{l}\text { Folded Plate } \\
\left(60^{\circ}\right)\end{array}$ & 99.89 & 87.89 & 93.89 & $\begin{array}{c}\text { Folded } \\
\text { Plate }\left(60^{0}\right)\end{array}$ & 98.67 & 89.22 & 93.94 \\
\hline
\end{tabular}

It is seen from Table 3 that all average accuracies are higher than $92.17 \%$. Such a high accuracy value indicates that the developed ANN models have successfully localized the considered cracks in all structures. For flat plates, y-dependent cracks have been located slightly better than those of $\mathrm{x}$-dependent. On the other hand, an opposite situation has been observed for folded 
structures. The $\mathrm{x}$-dependent cracks have been detected more accurately than those of $\mathrm{y}$ dependent cracks in these structures for most folded angles. The localization of both cracks in the $\mathrm{x}$-axis (throughout $\mathrm{a}_{\mathrm{p}}$ ) is so accurate that the accuracy values have been evaluated higher than $97.44 \%$ no matter which structure has been considered. On the other hand, the accuracy of localizing those cracks in the $\mathrm{y}$-axis (throughout $\mathrm{b}_{\mathrm{p}}$ ) has been obtained between $86.89 \%$ 98.56\% depending on the structure. Structure-wise comparison indicates that the cracks in the flat plates have been detected more accurately than those of folded plates. Considering all cracks and all structures, the average crack localization accuracy is $95.12 \%$. Figure 7 shows the damage localization accuracy of ANN for the flat plate structure for each $\mathrm{x}$-dependent and $\mathrm{y}$ dependent crack location respectively.

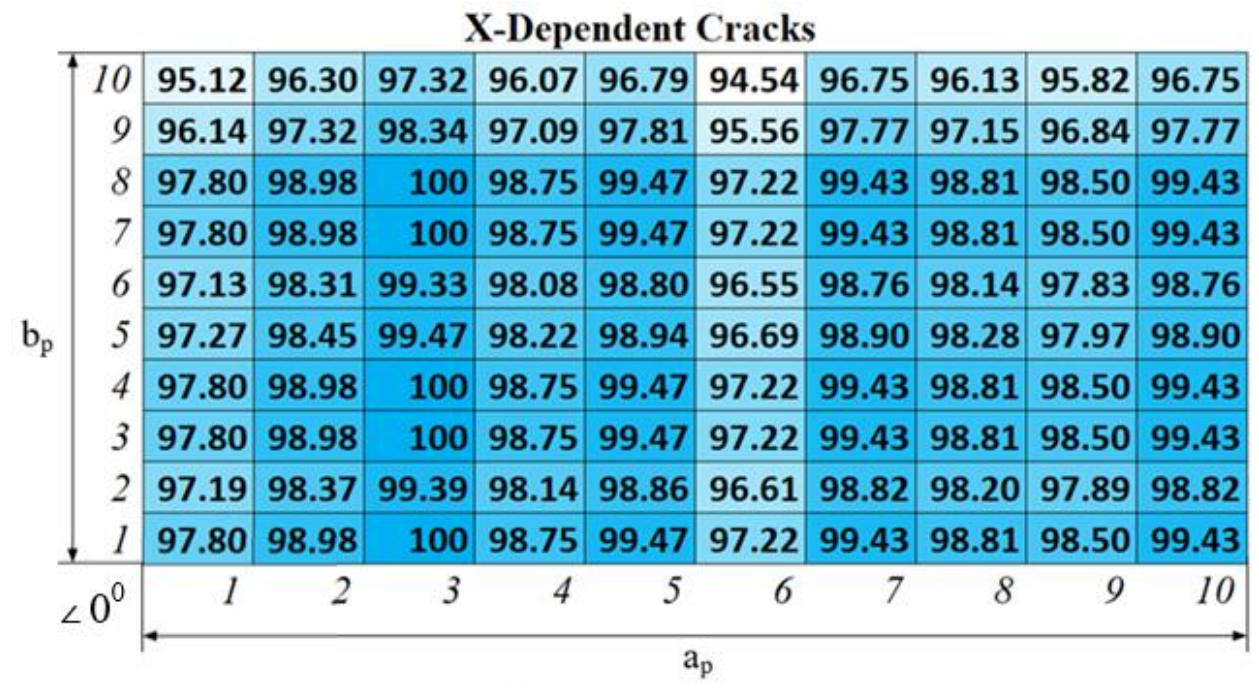

\begin{tabular}{|c|c|c|c|c|c|c|c|c|c|c|}
\hline \multicolumn{11}{|c|}{ Y-Dependent Cracks } \\
\hline$\uparrow 10$ & 95.49 & 97.32 & 97.32 & 97.32 & 96.83 & 96.83 & 96.13 & 95.54 & 96.26 & 96.76 \\
\hline 9 & 96.51 & 98.34 & 98.34 & 98.34 & 97.84 & 97.85 & 97.15 & 96.55 & 97.27 & 97.78 \\
\hline 8 & 98.17 & 100 & 100 & 100 & 99.51 & 99.51 & 98.81 & 98.22 & 98.94 & 99.44 \\
\hline 7 & 98.17 & 100 & 100 & 100 & 99.51 & 99.51 & 98.81 & 98.22 & 98.94 & 99.44 \\
\hline 6 & 97.50 & 99.33 & 99.33 & 99.33 & 98.83 & 98.84 & 98.14 & 97.54 & 98.26 & 98.77 \\
\hline$b_{p}$ & 97.64 & 99.47 & 99.47 & 99.47 & 98.98 & 98.98 & 98.28 & 97.69 & 98.41 & 98.91 \\
\hline 4 & 98.17 & 100 & 100 & 100 & 99.51 & 99.51 & 98.81 & 98.22 & 98.94 & 99.44 \\
\hline 3 & 98.17 & 100 & 100 & 100 & 99.51 & 99.51 & 98.81 & 98.22 & 98.94 & 99.44 \\
\hline 2 & 97.56 & 99.39 & 99.39 & 99.39 & 98.90 & 98.90 & 98.20 & 97.61 & 98.33 & 98.83 \\
\hline 1 & 98.17 & 100 & 100 & 100 & 99.51 & 99.51 & 98.81 & 98.22 & 98.94 & 99.44 \\
\hline$\angle 0^{\circ}$ & 1 & 2 & 3 & 4 & 5 & 6 & 7 & 8 & 9 & 10 \\
\hline
\end{tabular}

Figure 7. Crack localization accuracy values of flat plate for each $\mathrm{x}$-dependent and $\mathrm{y}$ dependent crack position.

As seen from Figure 7, both x-dependent and y-dependent cracks have been located by accuracy values higher than $94.54 \%$. As is indicated before, the average accuracy of localizing $y-$ dependent cracks is slightly higher than that of $\mathrm{x}$-dependent cracks. 
Figure 8 shows the crack detection accuracy values of ANN for the $15^{0}$ folded plate structure for each $\mathrm{x}$-dependent and y-dependent crack location respectively. The bold red line indicates the section where the structure is folded by $15^{\circ}$.

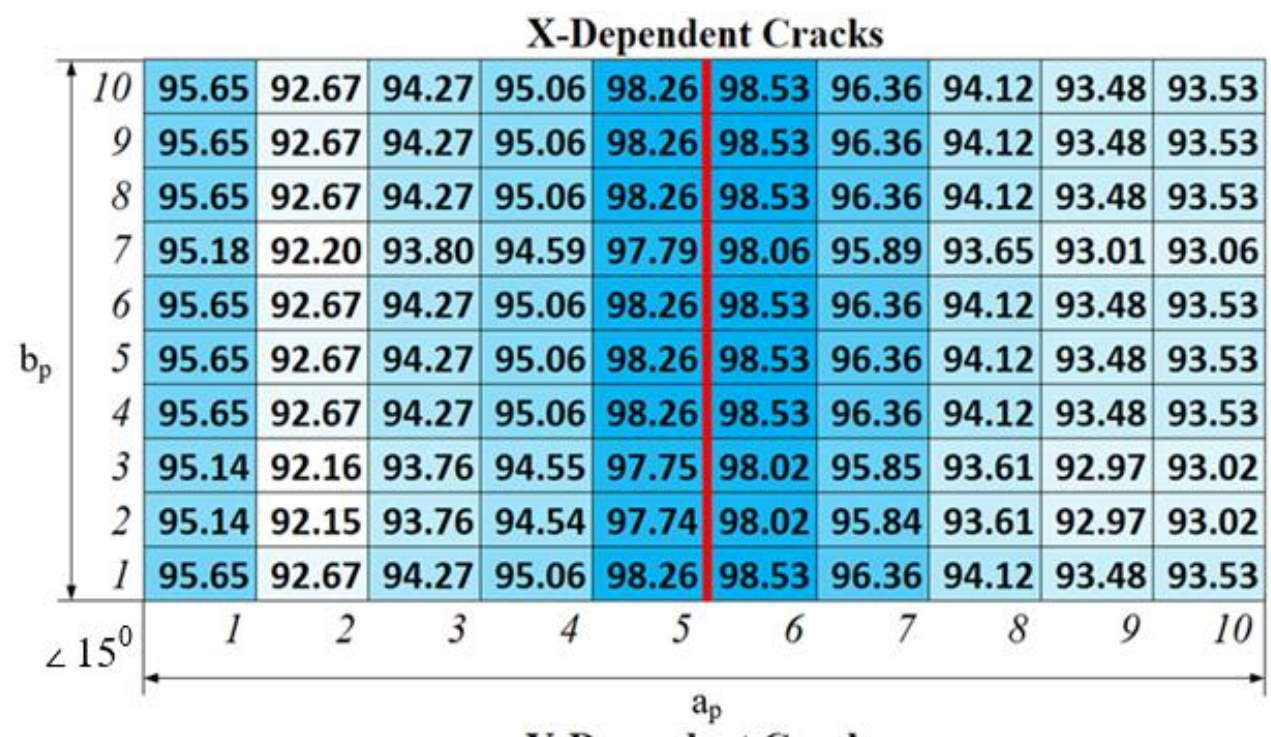

Y-Dependent Cracks

\begin{tabular}{|c|c|c|c|c|c|c|c|c|c|c|}
\hline 10 & 100 & 97.56 & 94.65 & 92.31 & 97.95 & 88.83 & 86.02 & 97.59 & 94.95 & 98.94 \\
\hline 9 & 100 & 97.56 & 94.65 & 92.31 & 97.95 & 88.83 & 86.02 & 97.59 & 94.95 & 98.94 \\
\hline 8 & 100 & 97.56 & 94.65 & 92.31 & 97.95 & 88.83 & 86.02 & 97.59 & 94.95 & 98.94 \\
\hline 7 & 99.53 & 97.09 & 94.18 & 91.84 & 97.48 & 88.36 & 85.55 & 97.12 & 94.48 & 98.47 \\
\hline 6 & 100 & 97.56 & 94.65 & 92.31 & 97.95 & 88.83 & 86.02 & 97.59 & 94.95 & 98.94 \\
\hline 5 & 100 & 97.56 & 94.65 & 92.31 & 97.95 & 88.83 & 86.02 & 97.59 & 94.95 & 98.94 \\
\hline 4 & 100 & 97.56 & 94.65 & 92.31 & 97.95 & 88.83 & 86.02 & 97.59 & 94.95 & 98.94 \\
\hline 3 & 99.49 & 97.05 & 94.14 & 91.80 & 97.44 & 88.32 & 85.51 & 97.08 & 94.44 & 98.43 \\
\hline 2 & 99.49 & 97.05 & 94.13 & 91.80 & 97.43 & 88.32 & 85.51 & 97.08 & 94.44 & 98.42 \\
\hline 1 & 100 & 97.56 & 94.65 & 92.31 & 97.95 & 88.83 & 86.02 & 97.59 & 94.95 & 98.94 \\
\hline$\angle 15^{\circ}$ & 1 & 2 & 3 & 4 & 5 & 6 & 7 & 8 & 9 & 10 \\
\hline
\end{tabular}

Figure 8. Crack localization accuracy values of $15^{0}$ folded plate for each $x$-dependent and ydependent crack position.

It is seen from Figure 8 that the cracks have been localized by accuracy values varying between $85.51 \%-100 \%$ no matter which kind of crack has been considered. Comparing with the flat structure, the average crack localization accuracy values of the folded structure with $15^{0}$ angles are smaller than those of the flat plate. Especially for the y-dependent cracks, the accuracy values fluctuate between $85.51 \%-88.83 \%$ for cracks located in the 6 th and 7 th columns. It is concluded that the ANN model detects some of those cracks as if they were located in the 5th and 8th columns. On the other hand, the y-dependent cracks positioned in the 1st are the most accurately localized ones since the localization accuracy values change between $99.49 \%$ $100 \%$. For x-depended cracks, the cracks that are the most accurately detected are located in the 6 th column. The localization accuracy in this region is evaluated between $98.02 \%-98.53 \%$ 
for these cracks. On the other hand, the least accurately detected $\mathrm{x}$-dependent cracks are located in the 2nd column by accuracy values changing between $92.15 \%-92.67 \%$.

Figure 9 shows the crack localization accuracy values of ANN for the $30^{\circ}$ folded plate structure for each $\mathrm{x}$-dependent and y-dependent crack location respectively. The bold red line indicates the section where the structure is folded by $30^{\circ}$.

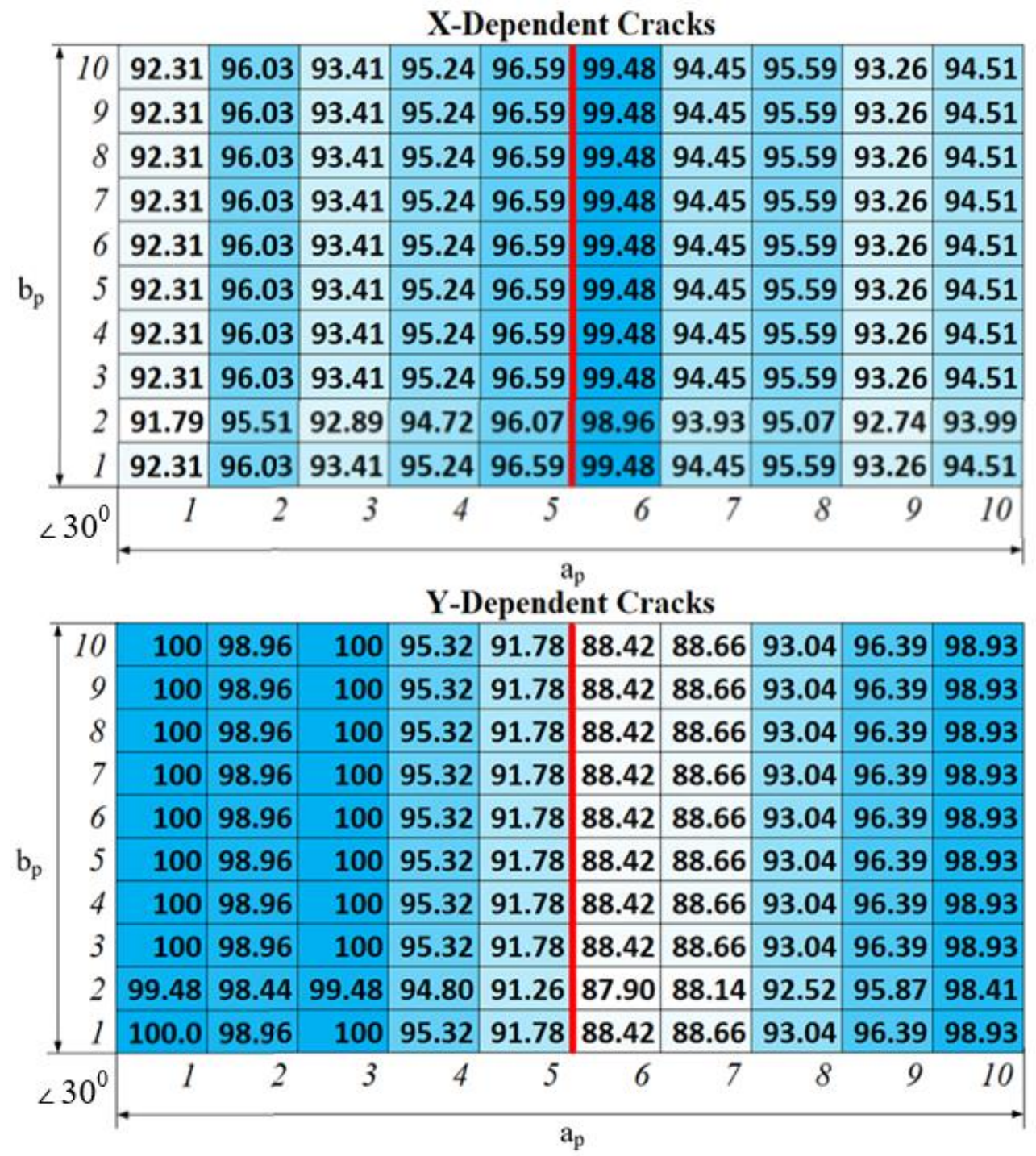

Figure 9. Crack localization accuracy values of $30^{\circ}$ folded plate for each $\mathrm{x}$-dependent and ydependent crack position.

It is seen from Figure 9 that both x-dependent and y-dependent cracks have been located by accuracy values between $87.90 \%$ - $100 \%$. Comparing with the $15^{0}$ folded plate structure, the average crack localization accuracy values of the $30^{\circ}$ folded structure are almost identical. A similar condition in terms the crack localization has been observed for $30^{\circ}$ folded structure as it has been seen for $15^{0}$ folded structures. One difference is the localization accuracy values of ydependent cracks for the $6^{\text {th }}$ and $7^{\text {th }}$, which differ between $87.90 \%-88.66 \%$ for the $30^{\circ}$ folded structure. Besides, the best localized y-dependent cracks are positioned in the $1^{\text {st }}$ and $3^{\text {rd }}$ 
columns for this structure. The best localization accuracy values of $15^{\circ}$ and $30^{\circ}$ folded structures are almost the same for this kind of crack. The other difference is the lowest localization accuracy values and locations of $\mathrm{x}$-dependent cracks. For the $30^{\circ}$ folded structure, the minimum accuracy values have been evaluated for the first column and range between $91.79 \%-92.31 \%$. On the other hand, for the $15^{0}$ folded structure, these values have been obtained for the $2^{\text {nd }}$ column and range between $92.15 \%-92.67 \%$. The best localization accuracy values for $30^{\circ}$ folded plate are slightly increased when compared with those of $15^{\circ}$. It is seen from Figure 9 that the best localization accuracy values vary between $98.46 \%-99.48 \%$ for $\mathrm{x}$-dependent cracks that existed in the $6^{\text {th }}$ column of the $30^{\circ}$ folded structure.

Figure 10 shows the crack localization accuracy values of ANN for the $45^{0}$ folded plate structure for each $\mathrm{x}$-dependent and y-dependent crack location respectively. The bold red line indicates the section where the structure is folded by $45^{\circ}$.

\begin{tabular}{|c|c|c|c|c|c|c|c|c|c|c|}
\hline \multicolumn{11}{|c|}{ X-Dependent Cracks } \\
\hline 10 & 98.53 & 93.75 & 95.12 & 94.45 & 95.88 & 98.72 & 97.98 & 94.74 & 93.89 & 93.11 \\
\hline 9 & 98.53 & 93.75 & 95.12 & 94.45 & 95.88 & 98.72 & 97.98 & 94.74 & 93.89 & 93.11 \\
\hline 8 & 98.53 & 93.75 & 95.12 & 94.45 & 95.88 & 98.72 & 97.98 & 94.74 & 93.89 & 93.11 \\
\hline 7 & 98.53 & 93.75 & 95.12 & 94.45 & 95.88 & 98.72 & 97.98 & 94.74 & 93.89 & 93.11 \\
\hline 6 & 98.53 & 93.75 & 95.12 & 94.45 & 95.88 & 98.72 & 97.98 & 94.74 & 93.89 & 93.11 \\
\hline 5 & 98.53 & 93.75 & 95.12 & 94.45 & 95.88 & 98.72 & 97.98 & 94.74 & 93.89 & 93.11 \\
\hline 4 & 98.53 & 93.75 & 95.12 & 94.45 & 95.88 & 98.72 & 97.98 & 94.74 & 93.89 & 93.11 \\
\hline 3 & 98.53 & 93.75 & 95.12 & 94.45 & 95.88 & 98.72 & 97.98 & 94.74 & 93.89 & 93.11 \\
\hline 2 & 98.01 & 93.23 & 94.60 & 93.92 & 95.35 & 98.20 & 97.46 & 94.21 & 93.37 & 92.58 \\
\hline 1 & 98.53 & 93.75 & 95.12 & 94.45 & 95.88 & 98.72 & 97.98 & 94.74 & 93.89 & 93.11 \\
\hline & 1 & 2 & 3 & 4 & 5 & $\sigma$ & 7 & 0 & 3 & 10 \\
\hline
\end{tabular}

Y-Dependent Cracks

\begin{tabular}{|c|c|c|c|c|c|c|c|c|c|c|}
\hline 10 & 91.25 & 99.40 & 100 & 91.92 & 90.41 & 82.28 & 84.74 & 92.94 & 96.39 & 99.44 \\
\hline 9 & 91.25 & 99.40 & 100 & 91.92 & 90.41 & 82.28 & 84.74 & 92.94 & 96.39 & 99.44 \\
\hline 8 & 91.25 & 99.40 & 100 & 91.92 & 90.41 & 82.28 & 84.74 & 92.94 & 96.39 & 99.44 \\
\hline 7 & 91.25 & 99.40 & 100 & 91.92 & 90.41 & 82.28 & 84.74 & 92.94 & 96.39 & 99.44 \\
\hline 6 & 91.25 & 99.40 & 100 & 91.92 & 90.41 & 82.28 & 84.74 & 92.94 & 96.39 & 99.44 \\
\hline 5 & 91.25 & 99.40 & 100 & 91.92 & 90.41 & 82.28 & 84.74 & 92.94 & 96.39 & 99.44 \\
\hline 4 & 91.25 & 99.40 & 100 & 91.92 & 90.41 & 82.28 & 84.74 & 92.94 & 96.39 & 99.44 \\
\hline 3 & 91.25 & 99.40 & 100 & 91.92 & 90.41 & 82.28 & 84.74 & 92.94 & 96.39 & 99.44 \\
\hline 2 & 90.73 & 98.88 & 99.48 & 91.40 & 89.88 & 81.76 & 84.21 & 92.41 & 95.86 & 98.92 \\
\hline 1 & 91.25 & 99.40 & 100 & 91.92 & 90.41 & 82.28 & 84.74 & 92.94 & 96.39 & 99.44 \\
\hline$\angle 45^{\circ}$ & 1 & 2 & 3 & 4 & 5 & 6 & 7 & 8 & 0 & 10 \\
\hline
\end{tabular}

Figure 10. Crack localization accuracy values of $45^{0}$ folded plate for each $x$-dependent and $y$ dependent crack position. 
As seen from Figure 10, all cracks have been localized by accuracy values higher than $81.76 \%$. Comparing with the $30^{\circ}$ folded plate structure, the average crack localization accuracy values of the $45^{\circ}$ folded structure are smaller than those of the $30^{\circ}$ folded plate structure. A similar condition in terms the crack localization has been observed for $45^{0}$ folded structure as it has been seen for $15^{\circ}$ and $30^{\circ}$ folded structures. For the y-dependent cracks the lowest accuracy values have been evaluated for the same locations of those of the $15^{\circ}$ and $30^{\circ}$ folded structures. However, the crack localization accuracy values in these rows vary between $81.76 \%-84.74 \%$. The highest localization accuracy values for $y$-dependent cracks have been obtained for the $3^{\text {rd }}$ column by $99.48 \%-100 \%$. Apart from the $15^{\circ}$ and $30^{\circ}$ folded structures, for $\mathrm{x}$-dependent cracks, the minimum accuracy values have been evaluated for the tenth column and range between $92.58 \%-93.11 \%$ for $45^{0}$ folded structure. On the other hand, the highest accuracy values for such kind of crack and $45^{\circ}$ folded structure have been obtained for the $6^{\text {th }}$ column by $97.98 \%$. Figure 11 shows the crack localization accuracy values of ANN for the $60^{\circ}$ folded plate structure for each $\mathrm{x}$-dependent and y-dependent crack location respectively. The bold red line indicates the section where the structure is folded by $60^{\circ}$.

X-Dependent Cracks

\begin{tabular}{|c|c|c|c|c|c|c|c|c|c|c|}
\hline 10 & 92.15 & 93.28 & 90.12 & 89.91 & 99.46 & 98.31 & 94.31 & 93.61 & 90.09 & 92.99 \\
\hline 9 & 92.69 & 93.82 & 90.66 & 90.45 & 100 & 98.85 & 94.85 & 94.15 & 90.63 & 93.53 \\
\hline 8 & 92.69 & 93.82 & 90.66 & 90.45 & 100 & 98.85 & 94.85 & 94.15 & 90.63 & 93.53 \\
\hline 7 & 92.69 & 93.82 & 90.66 & 90.45 & 100 & 98.85 & 94.85 & 94.15 & 90.63 & 93.53 \\
\hline 6 & 92.69 & 93.82 & 90.66 & 90.45 & 100 & 98.85 & 94.85 & 94.15 & 90.63 & 93.53 \\
\hline 5 & 92.69 & 93.82 & 90.66 & 90.45 & 100 & 98.85 & 94.85 & 94.15 & 90.63 & 93.53 \\
\hline 4 & 92.69 & 93.82 & 90.66 & 90.45 & 100 & 98.85 & 94.85 & 94.15 & 90.63 & 93.53 \\
\hline 3 & 92.69 & 93.82 & 90.66 & 90.45 & 100 & 98.85 & 94.85 & 94.15 & 90.63 & 93.53 \\
\hline 2 & 92.69 & 93.82 & 90.66 & 90.45 & 100 & 98.85 & 94.85 & 94.15 & 90.63 & 93.53 \\
\hline 1 & 92.69 & 93.82 & 90.66 & 90.45 & 100 & 98.85 & 94.85 & 94.15 & 90.63 & 93.53 \\
\hline$\angle 60^{\circ}$ & 1 & 2 & 3 & 4 & 5 & 6 & 7 & 8 & 9 & 10 \\
\hline
\end{tabular}

Y-Dependent Cracks

\begin{tabular}{|c|c|c|c|c|c|c|c|c|c|c|}
\hline 10 & 98.47 & 97.31 & 98.15 & 97.38 & 95.85 & 80.06 & 84.25 & 95.62 & 94.92 & 99.46 \\
\hline 9 & 99.01 & 97.85 & 98.69 & 97.92 & 96.39 & 80.60 & 84.79 & 96.16 & 95.46 & 100 \\
\hline 8 & 99.01 & 97.85 & 98.69 & 97.92 & 96.39 & 80.60 & 84.79 & 96.16 & 95.46 & 100 \\
\hline 7 & 99.01 & 97.85 & 98.69 & 97.92 & 96.39 & 80.60 & 84.79 & 96.16 & 95.46 & 100 \\
\hline 6 & 99.01 & 97.85 & 98.69 & 97.92 & 96.39 & 80.60 & 84.79 & 96.16 & 95.46 & 100 \\
\hline 5 & 99.01 & 97.85 & 98.69 & 97.92 & 96.39 & 80.60 & 84.79 & 96.16 & 95.46 & 100 \\
\hline 4 & 99.01 & 97.85 & 98.69 & 97.92 & 96.39 & 80.60 & 84.79 & 96.16 & 95.46 & 100 \\
\hline 3 & 99.01 & 97.85 & 98.69 & 97.92 & 96.39 & 80.60 & 84.79 & 96.16 & 95.46 & 100 \\
\hline 2 & 99.01 & 97.85 & 98.69 & 97.92 & 96.39 & 80.60 & 84.79 & 96.16 & 95.46 & 100 \\
\hline 1 & 99.0 & 97.85 & 98.69 & 97.92 & 96.39 & 80.60 & 84.79 & 96.16 & 95.46 & 100 \\
\hline$\angle 60^{\circ}$ & 1 & $?$ & 3 & 4 & 5 & 6 & 7 & 8 & 9 & 10 \\
\hline
\end{tabular}


Figure 11. Crack localization accuracy values of $60^{\circ}$ folded plate for each $\mathrm{x}$-dependent and ydependent crack position.

It is seen from Figure 11 that all cracks have been localized by accuracy values higher than $80.60 \%$. Comparing the $60^{\circ}$ folded structure with other folded structures, it can be concluded that the minimum localization accuracy values of y-dependent cracks have been evaluated for the 6 th and 7th columns for all folded structures. As it is concluded for $15^{\circ}, 30^{\circ}$, and $45^{\circ}$ folded structures, the only difference is the range of the accuracy values. For $60^{\circ}$ folded structure, these values ranges between $80.60 \%-84.79 \%$. The highest localization accuracy values have been obtained for the $10^{\text {th }}$ column by $99.46 \%-100 \%$. For x-dependent cracks, the minimum accuracy values have been obtained for the $3 \mathrm{rd}, 4 \mathrm{th}$, and 9 th rows. Although the minimum accuracy of the localization of $\mathrm{x}$-dependent cracks has been distributed in wider locations than those of the other folded structures, the localization accuracy values for these regions are still above $90 \%$. Apart from the other folded structures, for $60^{\circ}$ folded structure and $\mathrm{x}$-dependent cracks, the highest localization accuracy values have been obtained for the $5^{\text {th }}$ column by $99.46 \%-100 \%$.

\section{Conclusion}

In this study, the localization of various cracks in flat and folded plate structures has been performed by employing the Back-propagated Artificial Neural Networks (ANN). According to the results obtained within this study, the following conclusions have been drawn.

- The developed Back-propagated ANN has successfully located all cracks for all structures with an average accuracy of $95.12 \%$.

- It is concluded that $\mathrm{x}$-dependent cracks are localized slightly better than y-dependent cracks for flat plates. On the other hand, the opposite situation is observed for folded structures.

- The row or $\mathrm{x}$-axis (throughout $\mathrm{a}_{\mathrm{p}}$ ) of the cracks is more accurately detected than those of the column or $y$-axis (throughout $b_{p}$ )

- Considering all cracks and the type of the structures, the average accuracy values are evaluated from the highest to the lowest as the flat plate $(98.52 \%), 30^{0}$ folded plate $(94.78 \%), 15^{0}$ folded plate $(94.77 \%), 60^{\circ}$ folded plate $(93.91 \%)$, and $45^{0}(93.61 \%)$.

- The folding angles of the folded structures have an impact on the crack localization accuracy values. It can be concluded that performing crack localization on flat plate results in higher accuracy than folded structures. On the other hand, there is no strict behavior in terms of the variation of localization accuracy values among the folded structures considering the folding angles.

- No matter which folding angle has been considered, the minimum localization accuracy values for $y$-dependent cracks have been evaluated for the 6 th and 7 th column of folded structures. On the other hand, the maximum localization accuracy values for $y$ dependent cracks has been obtained for the 1st, 3rd, and 10th columns depending on the folding angle.

- Except for the $60^{0}$ folded structure, the maximum localization accuracy values of $\mathrm{x}$ dependent cracks have been evaluated for the 6th column of the structure. For the $60^{\circ}$ 
folded structure, this region has been shifted to the 5th column. Since the 5th and 6th columns are the closest regions to the folding line of the structure, it can be concluded that the best localization accuracies for $\mathrm{x}$-dependent cracks have been evaluated for the regions close to the folding line. On the other hand, the minimum localization accuracy values have been obtained for different regions depending on the folding angle.

\section{Acknowledgements}

Not applicable.

\section{Author's Contributions}

CG and OD conducted the literature search. CG performed the dynamic analysis of healthy and damaged structures. DBD performed the neural network analysis. CG, OD, and DBD interpreted the results, and wrote the article together.

\section{Author's Information}

Can Gonenli and Oguzhan Das have a Ph.D. in Machine Theory and Dynamics. Duygu Bagci Das is in the Ph.D. thesis stage in Computer Engineering.

\section{Funding}

Not applicable.

\section{Competing Interests}

The authors declare no competing financial interests.

\section{References}

[1] Tsou, P., \& Shen, M.-H. H. (1994). Structural damage detection and identification using neural networks. AIAA Journal, 32(1), 176-183. https://doi.org/10.2514/3.11964

[2] Yam, L. H., Yan, Y. J., \& Jiang, J. S. (2003). Vibration-based damage detection for composite structures using wavelet transform and neural network identification. Composite Structures, 60(4), 403-412. https://doi.org/10.1016/s0263-8223(03)00023-0

[3] Yam, L. H., Yan, Y. J., \& Wei, Z. (2004). Vibration-based non destructive structural damage detection. Key Engineering Materials, 270-273, 1446-1453. https://doi.org/10.4028/www.scientific.net/kem.270-273.1446

[4] Yeung, W. T., \& Smith, J. W. (2005). Damage detection in bridges using neural networks for pattern recognition of vibration signatures. Engineering Structures, 27(5), 685-698. https://doi.org/10.1016/j.engstruct.2004.12.006

[5] Chen, H. G., Yan, Y. J., \& Jiang, J. S. (2007). Vibration-based damage detection in composite wingbox structures by hht. Mechanical Systems and Signal Processing, 21(1), 307-321. https://doi.org/10.1016/j.ymssp.2006.03.013 
[6] Manoach, E., \& Trendafilova, I. (2008). Large amplitude vibrations and damage detection of rectangular plates. Journal of Sound and Vibration, 315(3), 591-606.

https://doi.org/10.1016/j.jsv.2008.02.016

[7] Paulraj, M. P., Majid, M. S., Yaacob, S., Rahiman, M. H., \& Krishnan, R. P. (2009). Statistical time energy based damage detection in steel plates using artificial neural networks. 2009 5th International Colloquium on Signal Processing \& Its Applications. https://doi.org/10.1109/cspa.2009.5069182

[8] Shih, H. W., Thambiratnam, D. P., \& Chan, T. H. T. (2009). Vibration based structural damage detection in flexural members using multi-criteria approach. Journal of Sound and Vibration, 323(3-5), 645-661. https://doi.org/10.1016/j.jsv.2009.01.019

[9] Elshafey, A. A., Haddara, M. R., \& Marzouk, H. (2010). Damage detection in offshore structures using neural networks. Marine Structures, 23(1), 131-145.

https://doi.org/10.1016/j.marstruc.2010.01.005

[10] Paulraj, M. P., Mohd Shukry, A. M., Yaacob, S., Adom, A. H., \& Krishnan, R. P. (2010). Structural steel plate damage detection using dft spectral energy and artificial neural network. 2010 6th International Colloquium on Signal Processing \& Its Applications. https://doi.org/10.1109/cspa.2010.5545247

[11] Nasiri, M. R., Mahjoob, M. J., \& Aghakasiri, A. (2011). Damage detection in a composite plate using modal analysis and artificial intelligence. Applied Composite Materials, 18(6), 513-520. https://doi.org/10.1007/s10443-011-9231-x

[12] Paulraj, M. P., Yaacob, S., Majid, M. S. A., Kazim, M. N., \& Krishnan, P. (2013). Structural steel PLATE damage detection using non destructive TESTING, frame energy based statistical features and artificial neural networks. Procedia Engineering, 53, 376-386. https://doi.org/10.1016/j.proeng.2013.02.049

[13] Kourehli, S. S. (2017). Application of extreme learning machine to damage detection of plate-like structures. International Journal of Structural Stability and Dynamics, 17(07), 1750068. https://doi.org/10.1142/s0219455417500687

[14] Alexandrino, P. da, Gomes, G. F., \& Cunha, S. S. (2019). A robust optimization for damage detection using multiobjective genetic algorithm, neural network and fuzzy decision making. Inverse Problems in Science and Engineering, 28(1), 21-46. https://doi.org/10.1080/17415977.2019.1583225

[15] Pan, J., Zhang, Z., Wu, J., Ramakrishnan, K. R., \& Singh, H. K. (2019). A novel method of vibration modes selection for improving accuracy of frequency-based damage detection. Composites Part B: Engineering, 159, 437-446. https://doi.org/10.1016/j.compositesb.2018.08.134

[16] Tan, Z. X., Thambiratnam, D. P., Chan, T. H., Gordan, M., \& Abdul Razak, H. (2019). Damage detection in steel-concrete composite bridge using vibration characteristics and artificial neural network. Structure and Infrastructure Engineering, 16(9), 1247-1261. https://doi.org/10.1080/15732479.2019.1696378 
[17] Padil, K. H., Bakhary, N., Abdulkareem, M., Li, J., \& Hao, H. (2020). Non-probabilistic method to consider uncertainties in frequency response function for VIBRATIONBASED damage detection using artificial neural network. Journal of Sound and Vibration, 467, 115069. https://doi.org/10.1016/j.jsv.2019.115069

[18] Oliver, G. A., Ancelotti, A. C., \& Gomes, G. F. (2020). Neural network-based damage identification in composite LAMINATED plates using frequency shifts. Neural Computing and Applications, 33(8), 3183-3194. https://doi.org/10.1007/s00521-02005180-3

[19] Gonenli, C., \& Das, O. (2021). Effect of crack location on buckling and dynamic stability in plate frame structures. Journal of the Brazilian Society of Mechanical Sciences and Engineering, 43(6). https://doi.org/10.1007/s40430-021-03032-2

[20] Groh, R. M. J., \& Weaver, P. M. (2015). Static inconsistencies in certain axiomatic higher-order shear deformation theories for beams, plates and shells. Composite Structures, 120, 231-245. https://doi.org/10.1016/j.compstruct.2014.10.006

[21] Donnell, L. H. (1976). Beams, plates and shells. McGraw-Hill.

[22] Petyt, M. (2015). Introduction to finite element vibration analysis. Cambridge University Press.

[23] Chandrupatla, T. R., \& Belegundu, A. D. (2002). Introduction to finite elements in engineering. Prentice-Hall.

[24] Guha Niyogi, A., Laha, M. K., \& Sinha, P. K. (1999). Finite element vibration analysis of laminated composite folded plate structures. Shock and Vibration, 6(5-6), 273-283. https://doi.org/10.1155/1999/354234

[25] Minsky, M., Papert, S., \& Bottou Léon. (2017). Perceptrons: An introduction to computational geometry. The MIT Press.

[26] Pedregosa, F. et al. (2011). Scikit-learn: Machine Learning in Python. Journal of Machine Learning Research, 12, 2825-2830. https://doi.org/10.5555/1953048.2078195 